This article was downloaded by: [UZH Hauptbibliothek /

Zentralbibliothek Zürich]

On: 06 January 2015, At: 10: 11

Publisher: Taylor \& Francis

Informa Ltd Registered in England and Wales Registered Number: 1072954 Registered office: Mortimer House, 37-41 Mortimer Street, London W1T 3J H, UK

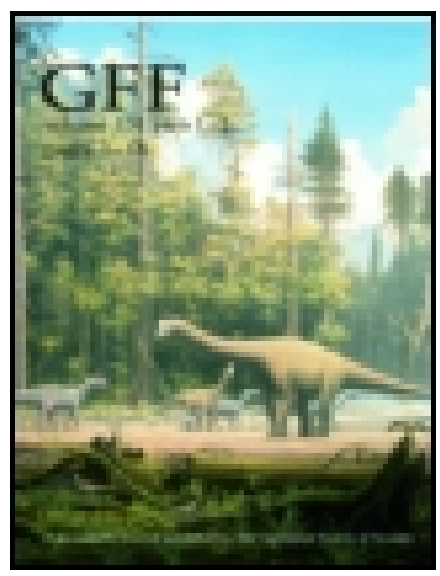

Geologiska Föreningen i Stockholm Förhandlingar

Publication details, including instructions for authors and subscription information: http:// www.tandfonline.com/ loi/ sgff19

\title{
Geologisk öfversigtskarta öfver Vermlands län
}

A. E. Törnebohm

Published online: $06 \mathrm{~J}$ an 2010.

To cite this article: A. E. Törnebohm (1881) Geologisk öfversigtskarta öfver Vermlands län, Geologiska Föreningen i Stockholm Förhandlingar, 5:12, 568-570, DOI: 10.1080/11035898109443974

To link to this article: http:// dx. doi. org/ 10.1080/ 11035898109443974

\section{PLEASE SCROLL DOWN FOR ARTICLE}

Taylor \& Francis makes every effort to ensure the accuracy of all the information (the "Content") contained in the publications on our platform. However, Taylor \& Francis, our agents, and our licensors make no representations or warranties whatsoever as to the accuracy, completeness, or suitability for any purpose of the Content. Any opinions and views expressed in this publication are the opinions and views of the authors, and are not the views of or endorsed by Taylor \& Francis. The accuracy of the Content should not be relied upon and should be independently verified with primary sources of information. Taylor and Francis shall not be liable for any losses, actions, claims, proceedings, demands, 
costs, expenses, damages, and other liabilities whatsoever or howsoever caused arising directly or indirectly in connection with, in relation to or arising out of the use of the Content.

This article may be used for research, teaching, and private study purposes. Any substantial or systematic reproduction, redistribution, reselling, loan, sub-licensing, systematic supply, or distribution in any form to anyone is expressly forbidden. Terms \& Conditions of access and use can be found at http:// www.tandfonline.com/page/terms-and-conditions 
Malnforekomsterna, hvilka hufvudsakligen äro bundna vid granulitbildningarnc, äro a kartan utmärkta si fullstñndigt, som skalan medgifvit. Talrikast äro jernmalenerna; genom variationer $i$ beteckningen angifres om malmen är bloustens- eller startmalm, samt äfren $i$ maingn fall om den ar qiartsig, balkig eller atfoljd af pyroxencller nmfibol-skarn.

Blad N:o 7, som i norr konnckterne med blad N:0 4, omfattar trabten mellan Vellern och norrn Vettern; $i$ nordost sträcker sig dess omrd̊de upp till Nerikesslätten. Här forekommande bergarter üro till stor del sydliga fortsăttningar of de ofran onmämnda pa blad N:O 4, dock spela granulitbildiningarne här endast en ganska underordnad rol, $i$ foljd hvaraf berggrundens sammansăttning ock är vida mindre vexlande.

Inom kartområdets vestra del äro gneiser rådancle, analoga med dem i Vermland, dels grá, inestadels randiga, dels jerngueis med inlagringar af hyperit; $i$ dess östra del hiro hter gneis, gucisgranit och granit på müngfaldigt sätt blandade medl hvarandra. Ofvaupå jerngneisen i vester följer här en grof urgranit kring sjön Viken, och pà deuna en gri, medelgrof urgranit, som har sin hufvudsakliga utbredning kring sjön Undeu (Undengranit). Denua sistnämnda med dènsamma atföljande gnoiser synes ligga $i$ én gcotektonisk skäl; i norr begränsas den neml. af en grof gneisgranit lik den vid Viken. Öster om norra ändan af Vettern trälfas îfven Undengranit, härr dock Lvilande på granulit, hvilken i sin ordning underlagras af rōd urgranit och gneis. Sảsom inlagringar i granuliten forckomma flera mättiga knlkstensbildningar, affensom Ammebergs bekanta zinkmalmer, bvilkas geognostiska förhaillanden något nñrmare omordas. Yugre än samtliga de kristalliniskt-skiffriga bergarterma äro de stora massor af grof granit, liknande Filipstadsgtaniten, hvilta uppträla kring Vetterns nordligasto del.

De betydande kambriska och siluriska aflagringarue dels pù Nerikesslätten, dels vid Vettern och Lugnoss samt pi Billingen och Kiunukulle blifra cndast $i$ största korthet till siun hufvuddrng onınämuda. A: $E$. $\boldsymbol{T}$.

Tönnebous, A. E. Geologisk ofversigtskarta ofter Vermlanls liin, med beskrifning.

Kartan, hvilken blifvit upprättad pa bekostnad af Vermlands linns I sandsting, är ämnad att dsskådliggöra Vermlands bergbjggund och framställer derför, så detaljeradt som deu lilla skalau, $1: 400000$, tilläter, linncts berggrund sidan dell skulle visa sig om de lösa aflag. ringaruc vore bortn. Tydligt framträdọ ock de geognostistin shiljaktigheter, som förcfinnas mellan läncts olika delar; i östẹ scr man de af viildign granitmassor omslutın inalmforande granulitomridena, 


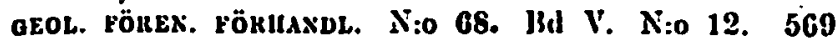

soln betinga grufvedriften inom Filipstads bergslag, $i$ läncts midt iir ater jerngneis med liyperit fortherrskande inom on bred zou, hvilken frin nordvestliga Vermland sträcker sig ned till Venern mellau Karlstad och Kristinchamn; läugst i vester och sydvest uppträda mera vexlande bergarter, öfrervägando dock af gneisig natur. Syclvestrn Vermland $\mathbf{n} r$, sassom forf. $\mathrm{i}$ beskrifningen frambåller, siirdelcs egnadt for ett studium af urformationens byggnad, cmedan der formationcus lagrade bergarter inom ett ganska betjdnnde omradde blifvit sá rogn rubbade frän sitt ursprungliga lägc, att deras inbördes lagerordning utan svårighet lan bestämmas. Synnerligen ür så förbillandet inom den stora geotektoniska skalbildning, som förcfinues vid Glafofjorden, och inom hvilken ett af granulitisin och glimmerskifferartade bergarter beståendo lag utgōr ett särdcles goult lecllagcr. De vigtignste länkarne inom sydvestra Vermlauds urformation äro i orduing uppifrån - nedait:

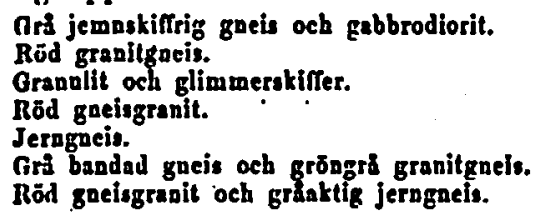

Såsom anmärkniugsvärdt framhålles, att samtliga de olika gneiscran i sjdrestra Vermland blifin i sin fortsittuing mot $\mathbf{S}$. mer och unç granitiska -och ôfvergá, ungefár vid gräusen mot Dalslaud, i mer eller mindre massformiga urgraniter.

Enformigheten -inom mellersta Vermlands stora jerugneisomräde nfbrytes nf derstädes pi en mängd ställen befintliga hyperitförckomster. Största antalct af dessa anser forf. uppträda såsom bäldar, dels mellan, dels $p \mathfrak{a}$ jerngneiscns lager; dock snknas cj excmpel pa att byperiten äfven kan billin gängar. Inom jerngneisomridets östra del Ülir bergartei grōfre och merı granitartad i samma mån man uärnar sig de stora granitmassorna inom läucts östliga delar. Den mängd olike granitarter, som här fortkomma, grupperas efter vissn hufvudtyper i urgranit, Filipstadsgranit, Jernagranit och yngre granit.

Blaṇd granulitounsådena är det kring sjön Ingen bade det största och det $i$ friga om lagerföljen fullstândigaste. Det kan geognostiskt indelas i trenne afdelningar, den undre bestående af ljus, mestadels gri granulit, den öfre af mörk hälleflinta och lerskiffer. 1'a gränsen mellani båda afdeluingarna förcfinnes en dioritbädd, stun. dom attooljal af tumilnande billningar. I liggandet af denan bädd uppträda Långbans och Pajsbergets' malmiforande dolomitstockar.

Med undantag af urgraviterna, och möjligen en del af Filipstadsgraniten, ïro samtliga graniter yngre ñı granulitbildningarne. Samtidiga med ilessả sistnäinnda ăro några porfýrer oclı porfyroider, yugre ater gangformigt uppträdlande dinbns, af hivilken bergart tvenuc varietcter sẫrskiljas, bronzitdiabas och olivindiabas.

I beskrimingens sista afteluing lemnas en kort öfverblick ôfver Verınlnuds vigtignste tekniska forckomster med sarrskildt fistadi af- 


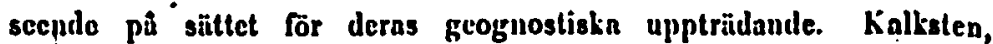
täljsten, glimmerskifier, lerskifitr sant malmer af olika slag blifva der omordade:

A. E. 'T.

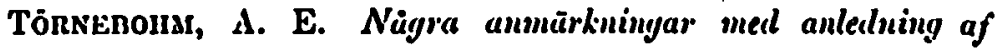
d:r SvenoNII uppsats "Om den s. k. Secegruppen i nordligaste Jïmtland och Angermanlandn, G. F. F. N:0 67.

I nämnila uppsats har d:r $F$. Svesosius lemuat en redo. görclse Tor en dol af siun iatttngelser under en geologisk resa $i$ Sveriges nordliga provinger. Särslildt beslrifver han forhüllnudeun vid Aborrfallet i Sjougdelfven, der quartsit och fossilforabde alun. skiffer forckomma. Enligt hr S:s uppgifter utbrederer sig W. oln Morrfnllet forst elt omraide nf quartsit, sà ett af röll sandsten och derefter ott af yvartsitskiffer, glimmerslifier och hornblendeskiffer af. snmmn beskaftenhet, son sả ofta träffas i Jemtlands och Vestcrbotteus fjüll och af mig blifvit sammanförda under benñ̈ıningen Scre-. gruppen.

Qurtsiten vid Aborrfallet har ler $\mathbf{S}$. funnit underlagra aluuskifícn, och hãraf synes han, sấ vida man nf hans nảgot ollarn frumstâllning fâr dōma, vilja oluta, ntt forthilllandet skullo vara detsamnıa soed Sevegruppens samtliga bergarter $i$ denna trakt. Bevisforingeu For en siddan uppfattning synes anig emellertid icke sărdeles bindanide. Att alunskiffern vid Aborrfnllet hvilar $p^{\mathfrak{a}}$ qvartsit synes enl. hr S:s uppgiftur vara temligen gifvet, men detta strider ingalundn mot ildre observationer, ty mig veterligen har ingenstädes uti Jemtland alunskiffer funnits hvila omedelbart på någon anuan bergart. Firugan iir forst, huruvida quartsiten uuder alunskifferu vid Aborrfallet iir satuma gcologiska bildning som den II. derom i stora massor förekommande, och scdan huru de läugre i W. uppträdande bildningarne, den rödn sandstenen och de tristalliniska skiffrarne, forlsälla sig till qvartsiten. Dessa frôgor blifva emellertid af hr S. gansila ofullstindigt utredda. Att qvartsiten vid Aborrfallet skulle vara af sainma geologiska âlder som den W. derom synes lyr $\mathbf{S}$. helt enkelt tagn för gifvet; huru han deremot tünker sig forhaillandet mellan qvartsiten och de vestra fulten, dorom erhaller man $i$ hans uppsats ej uigon bestāmd upplysning. Filigt de uppgifua stupuingsforliallandena skulle qvartsiten vara den underlagrande; kring det ãldre granitpartict SSW. On Norrsjōn sluta sig dock omcelelbart saudsteu och sliffrar utan någon inellnuliggande qvartsit. Förhallandet mellaw quartsiten, sandstenen och de kristalliniska skiffrarne blir genom br S: uppgifter ingalunda utredt '). Om man ock med hr S. skullo

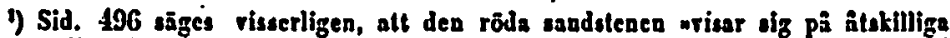
ställen tydligt underlagra yeartsiter oeh grárackeartade lerskiffrar, uti 